\title{
Acid Phosphatase Activity in the Chick's Inner Ear
}

\author{
Glenn M. Cohen* and Toshishige Kido**
}

*Troy State University, Department of Biological and Environmental Sciences, Troy, AL 36082

**Yamaguchi School of Medicine, Yamaguchi, Ube, 755 Japan

Acid phosphatase (AP) is the best known of the approximately 50 lysosomal enzymes [1]. AP activity is readily identifiable at the light microscopic level as intensely stained granules (reaction product). Although several investigators described the localization and distribution of AP activity in the mammalian inner ear [2-5], we found only one report about the occurrence of AP in the avian inner ear [6]. In the present study, our objective was to demonstrate the localization and distribution of AP activity in the chick's inner ear (membranous labyrinth) using the simultaneous coupling azo dye method [7] and to compare the avian results with those of mammals.

After newly hatched chicks were sacrificed, their ears were fixed for $2 \mathrm{hrs}$ in $2.5 \%$ glutaraldehyde (GA) or $2.5 \%$ paraformaldehyde (PFA). The membranous labyrinths were dissected out, dehydrated in either a graded series of acetone (used only for $2.5 \%$ GA fixation specimens) or $\mathrm{N}, \mathrm{N}$ dimethylformamide (DMF), and embedded in JB-4 (Polysciences, Warrington, PA), a methacrylate plastic. These sections were incubated for 1 or $2 \mathrm{hrs}$ at $37^{\circ} \mathrm{C}$ in an incubation medium (pH 5.0) containing naphthol AS-BI phosphate as substrate and hexazonium pararosaniline as a coupler that used the azo-coupling method [7]. In some instances, intact, fixed whole specimens were incubated in an aliquot of the same incubation medium as that of sectioned specimens and then dehydrated with DMF, embedded in JB-4 or LR White, and sectioned. For control specimens, either a substratedeficient medium or an incubation medium containing cupric sulfate $(0.002 \mathrm{M})$ was used. Methyl green was used as a nuclear stain.

The distribution pattern of AP activity in the hair cells from distal to proximal region in the basilar papilla was similar. Intense AP activity, as represented by a dense red reaction product, was detectable in the supranuclear area of almost all hair cells in the basilar papilla and vestibular sensory hair cells (FIG. 1) and agreed with Marmo's earlier findings [6]. Although distribution patterns were similar, AP activities differed among hair cell types and are presumably related to functional differences. In particular, hair cells of lagenar macula were most often characterized by intense AP activity in the subcuticular area (FIG. 1). The functional significance of high levels of AP in hair cells is undoubtedly related to their metabolic activity. For example, Ishii and Balogh [2] provided morphological evidence for autophagic activities in hair cells evidenced by, lipofuscin-like substances within lysosomes in their electron micrographs of hair cells. It has long been contended that non-sensory hair cells such as stria vascularis, external spiral sulcus cells and those around the macula and cristae ampullares help to regulate the ionic composition of endolymph $[3,4]$. In the present study, the columnar cells and the cells of the tegmentum vasculosum showed moderate to strong AP activity, and the transitional epithelia of the cristae ampullares also showed strong AP activity (FIG. 1). The dark cells help to regulate the ionic composition of endolymph and perilymph [5]. In the present study, intense AP activity of dark cells was concentrated in the supranuclear area or diffusely in the cytoplasm. These results show that AP activity is highest in cells with highest levels of transport activities for the production and maintenance of endolymph [6]. The wall cells and supporting cells of the vestibular labyrinth showed no enzyme reaction product. Statoacoustic 
and vestibular ganglion cells showed varying degrees of AP activity (FIG. 1). Embediments also influenced staining intensity. For example, sections of statoacoustic and vestibular ganglion cells cut from LR White blocks displayed more intense AP activity than those sections cut from JB-4 blocks. AP activity was also stronger in specimens fixed in $2.5 \%$ PFA than in $2.5 \%$ GA. In brief, intracellular traffic converges on lysosomes from various synthetic and degradative pathways related to secretion, phagocytosis, endocytosis, organelle turnover (autophagy) [1]. By extension, AP activities in the epithelial cells of the chick's inner ear parallel the generalized patterns of intracellular traffic to lysosomes that occur among cell types in other tissues and in turn reflect routine cellular metabolism.

\section{References}

[1] G. Karp, Cell and Molecular Biology, $3^{\text {rd }}$ ed., John Wiley \& Sons, New York (2002) 311-313.

[2] T. Ishii and K. Balogh, Acta Otolaryngol. 62 (1966) 185.

[3] R.S. Kimura et al., Acta Otolaryngol. 57 (1964) 517.

[4] K. Kikuchi and D.A. Hilding, Acta Otolaryngol. 62 (1966) 277.

j[5] R.S. Kimura, Ann. Otol. Rhinol. Laryngol. 78 (1969) 542.

[6] F. Marmo, Acta Embryo. Morphol. Exp. 8 (1965) 170.

[7] T. Barka and P.J. Anderson, J. Histochem. 10 (1962) 741.

[8] This research was supported in part by grants from the Deafness Research Foundation and American Hearing Research Foundation. The research was conducted at the Florida Institute of Technology, Melbourne, FL 32901.
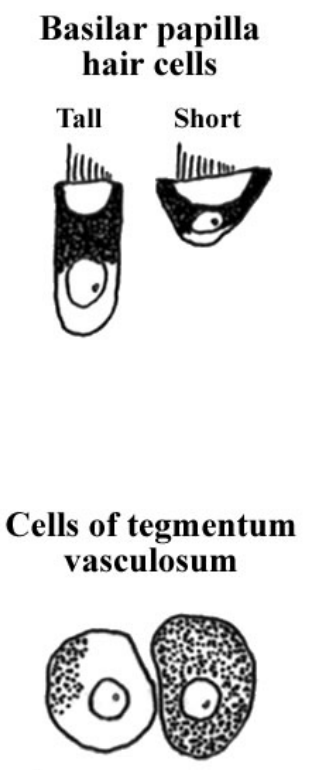
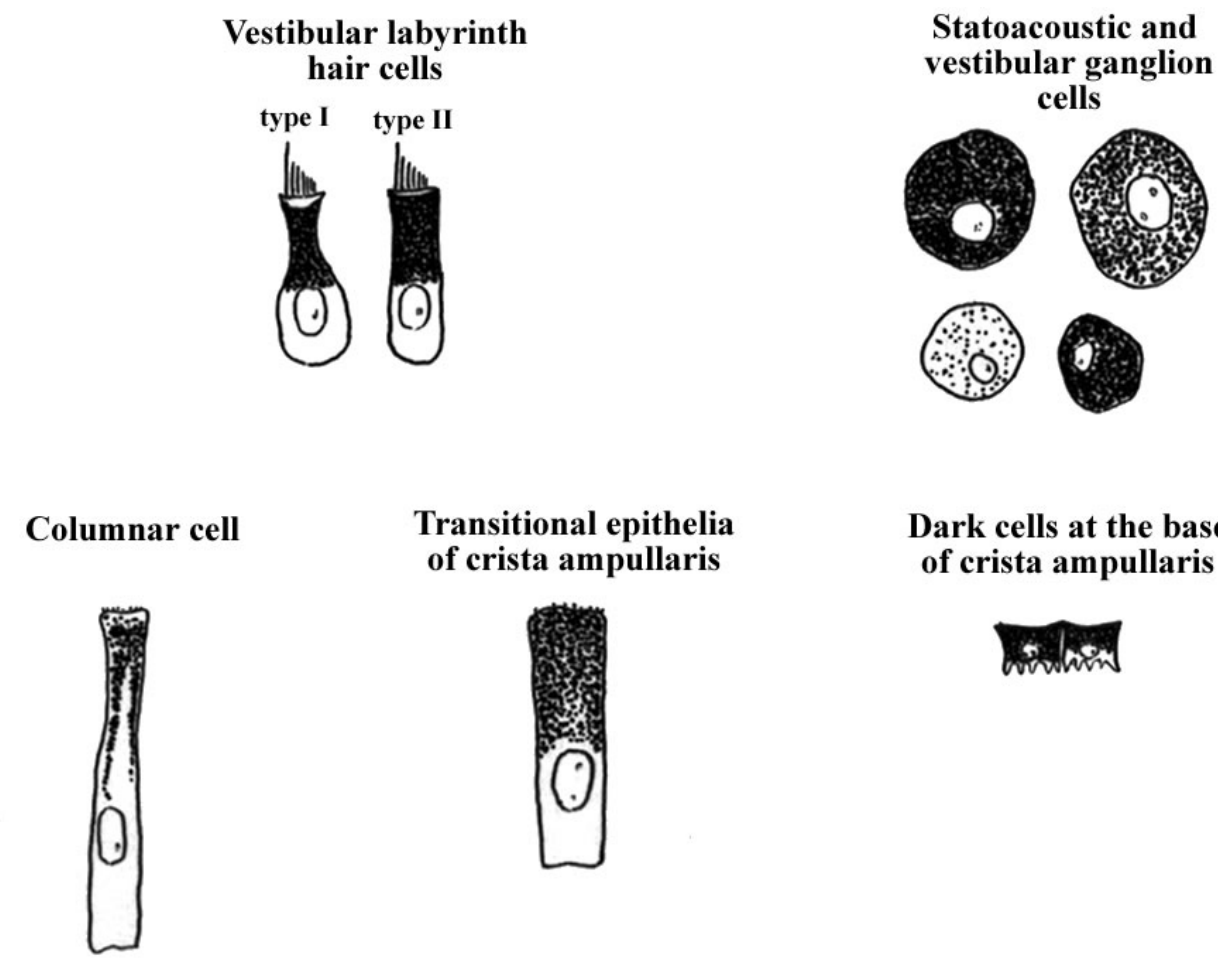

Dark cells at the base of crista ampullaris

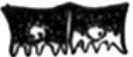

FIG. 1. Schematic representation of acid phosphatase activity in epithelial cells of the chick's inner ear. Solid black areas indicate elevated activities, whereas black dots represent individual granules. 